\title{
On the shoulders of giants
}

\author{
Peter A.M. Anderson, BSC, MD, FRCSC
}

See related article on page 293

W

ho does not want to leave a legacy? It is a basic human desire, maybe even a need, to leave something on this earth that in some way marks that we were here, albeit for a blink in time. In life we do this by what we build and the children we create and nurture. In the medical world we can create a legacy in several ways: by teaching, by patient care and by research. Of these 3 categories, research lends itself to perhaps the most objective measure by the application of simple mathematics. In this issue of CUAJ, Hennessey and colleagues ${ }^{1}$ present their results in the search for "The top 100 cited articles in urology." Within the limitations of the methodology, these cited articles provide a history of the important milestones of our specialty from 1965 to the present. The start point of 1965 reflects the limit of the databases, which therefore leaves out some pivotal articles that form the basis of many subsequent breakthroughs: Halifax-born Nobel laureate Charles Huggins and his description of the relationship between the hormonal milieu and the progression of prostate cancer is an example, since his seminal work was published before 1965 (he was awarded the Nobel Prize in Medicine in 1966).

Another limitation of the methodology is the anglophone dominance of the journals that were searched: $92 \%$ of the 93 journals are published in the English language. Although, as a unilingual anglophone, this ratio does reflect my reading preference, I am not confident that it truly reflects the worldwide experience. For instance, is it possible that Chaussy and colleagues' 1982 paper describing the use of extracorporeal shock wave lithotripsy (number 92) was also published in their native German language? It is also apparent that certain subspecialties of urology are underrepresented, possibly because of the decisions by the authors concerning which journals to include. The complete absence of articles related to pediatric urology can be explained by this bias.

We also must not confuse popularity with importance.
In a quick scan of the top 10 papers (anyone reminded of Letterman?) you will not find Walsh and Donker's initial description of the nerve-sparing radical prostatectomy technique (number 51), Morales and coauthors' report on the use of bacille Calmette-Guérin to treat superficial bladder tumours (number 52) or Lapides and colleagues' experience with clean intermittent catheterization (number 87), 3 innovations which revolutionized their respective areas of urology. Nonetheless, the numbers do not lie: Feldman and colleagues' 1994 paper reporting on impotence in the Massachusetts male aging study, with 1435 citations, was the most cited urology article in the English language. At the very least, this observation behooves every urologist and resident to be familiar with this work. Perhaps journal clubs across the country should plan to review every article on the top 100 list over a time frame of several years. This exercise would certainly be an interesting journey through the last 44 years of our specialty, and provide perspective to the current body of knowledge that we consider "facts."

The authors are to be congratulated for providing a road map for the journey of urology from 1965 to 2007. It should serve as a reminder that knowledge acquisition is a cumulative activity; in the words of Sir Isaac Newton, who wrote in a letter to Robert Hooke in 1676, "If I have seen further it is by standing on the shoulders of giants."

Professor, Department of Urology, Dalhousie University, Halifax, NS

Competing interests: None declared.

\section{Reference}

1. Hennessey K, Afshar K, MacNeily AE. Top 100 cited articles in urology. Can Urol Assoc J 2009;3: 293-302.

Correspondence: Dr. Peter Anderson, 2935 South Victoria, 5 th floor, QEll Health Sciences Centre VG Site, Halifax NS B3H 2Y9; fax 902 473-5855; peter.anderson@iwk.nshealth.ca 